\title{
CORRECTION
}

\section{Correction: Strategies Employed by Citizen Science Programs to Increase the Credibility of their Data}

\author{
Amy Freitag*, Ryan Meyer ${ }^{\dagger}$ and Liz Whiteman ${ }^{\dagger}$
}

This article details a correction to: Freitag, A., Meyer, R. \& Whiteman, L., (2016). Strategies Employed by Citizen Science Programs to Increase the Credibility of Their Data. Citizen Science: Theory and Practice. 1(1), 2. DOI: http://doi.org/10.5334/cstp.6

\section{Correction}

After publication of Freitag, A., Meyer, R. \& Whiteman, L., (2016) it was brought to light that a small number of data errors and definitions were incorrect or required clarity. These errors do not compromise the central purpose and conclusions of the paper, with all other content remaining valid. The authors take responsibility for the occurrence of the errors. Details of the required corrections are below, along with the relevant page number of the original publication.

\section{Table 1}

Errors were present within the original Table 1 (p. 4-5) concerning the "Beach Watch" data (row 1) and the resulting "\% employing strategy" (bottom row). The corrected Table $\mathbf{1}$ is presented below.

\section{Definitions}

Two of the "credibility strategy" definitions (p. 6-7) required minor edits to provide clarification. The corrected text is given below.

\section{* Virginia Sea Grant, US}

+ California Ocean Science Trust, US

Corresponding author: Amy Freitag (afreitag33@gmail.com)
- For the section "In the field" point 2 should read:

2. In-person oversight - Many data errors happen in the field. To address this, some projects designate staff, science partners, or "expert" volunteers to directly oversee data collection (indicated as a "yes" in the table if in-person oversight is always part of volunteer data collection).

- For the section "In the office," point 5 should read:

5. Quality assurance protocol - For some topics, standard quality assurance protocols are a required part of scientific practice in order to calibrate methods, technology, and practice over time. For citizen science, these protocols also certify volunteer capability in addition to the methods. "Yes" in the table indicates that a QA protocol, broadly recognized as an accepted standard, is available and required.

\section{Reference}

Freitag, A., Meyer, R. and Whiteman, L., 2016. Strategies Employed by Citizen Science Programs to Increase the Credibility of Their Data. Citizen Science: Theory and Practice, 1(1): 2. DOI: http://doi.org/10.5334/ cstp.6 


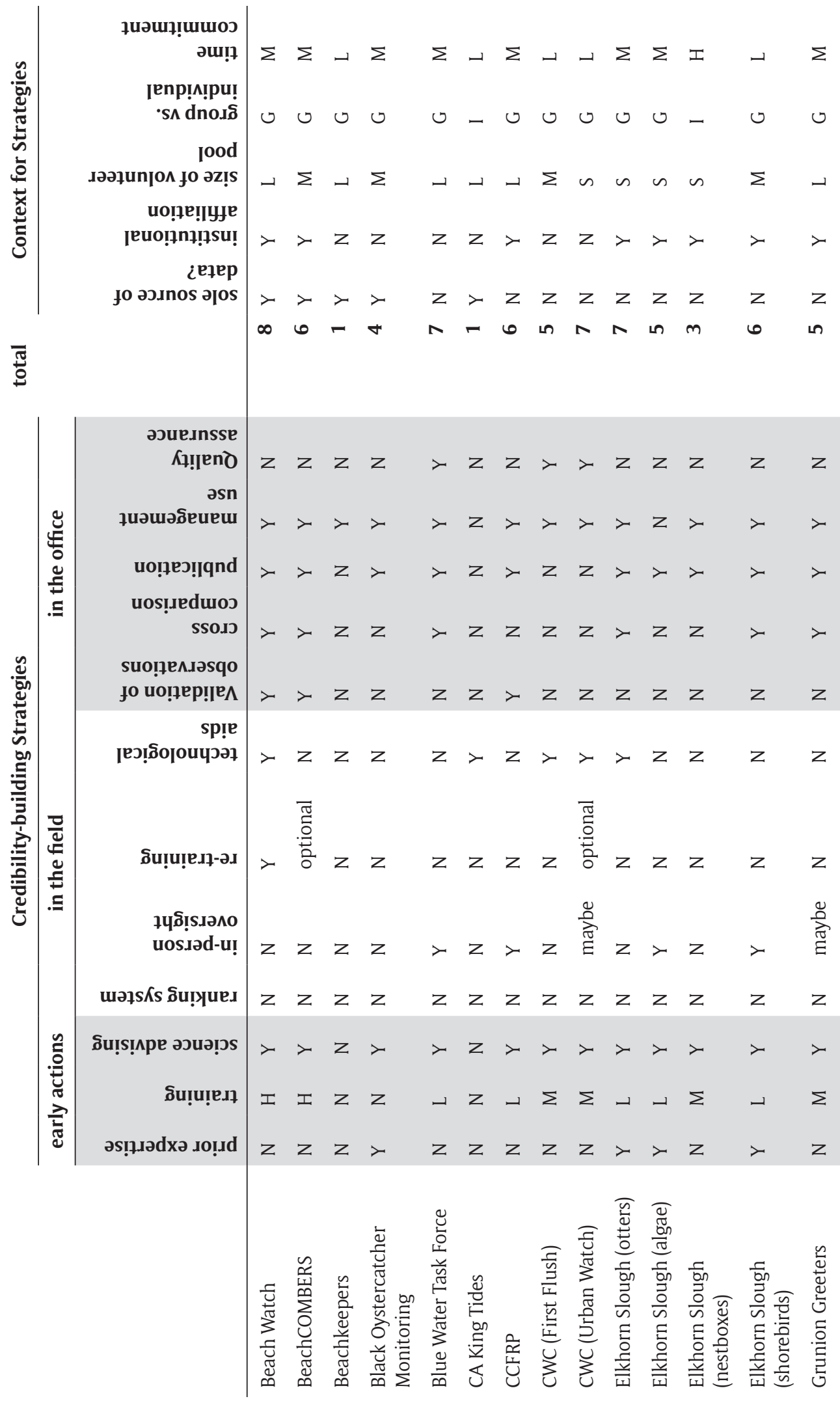




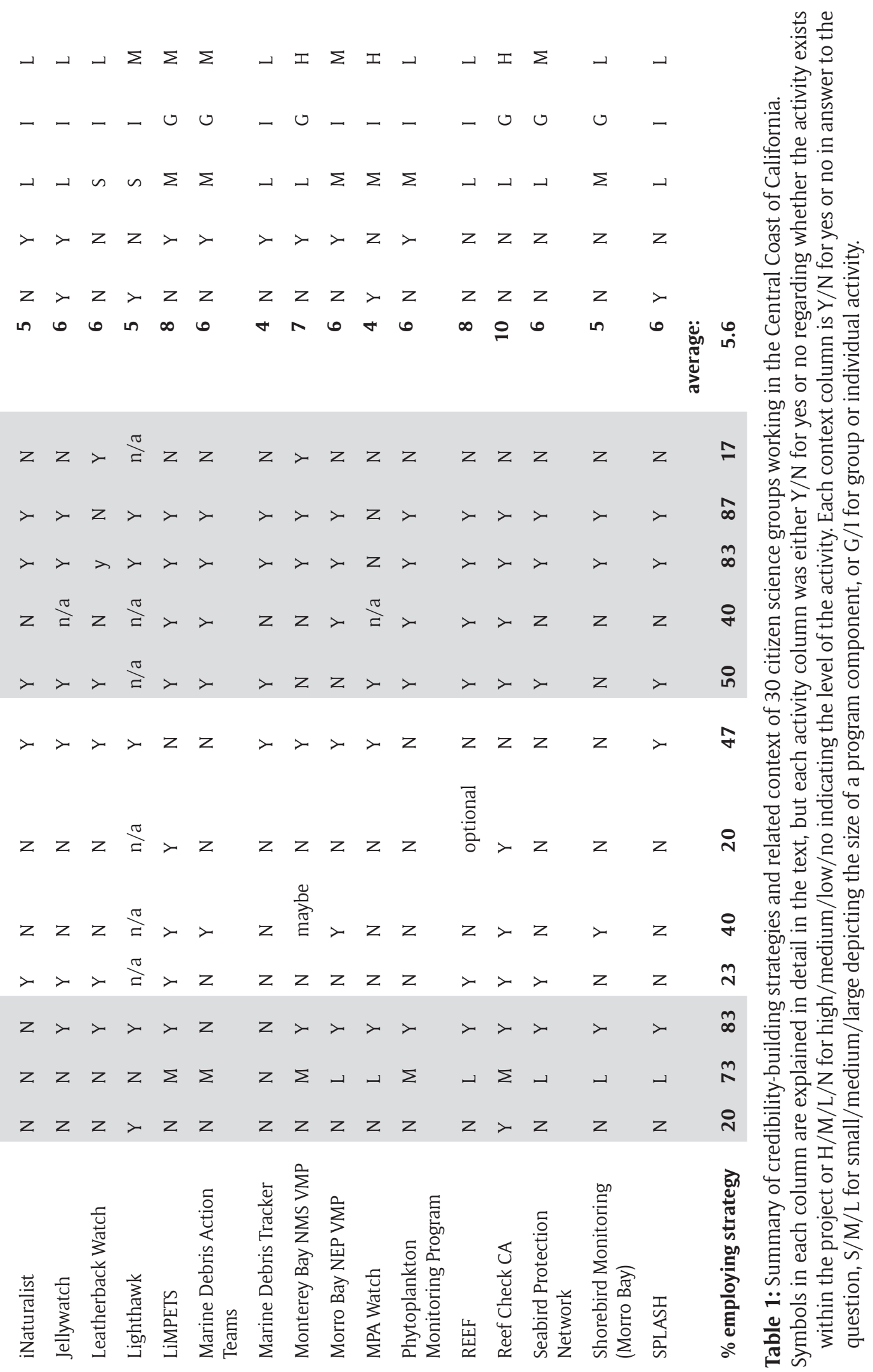


How to cite this article: Freitag, A, Meyer, R and Whiteman, L 2016 Correction: Strategies Employed by Citizen Science Programs to Increase the Credibility of their Data. Citizen Science: Theory and Practice, 1(2): 12, pp. 1-4, DOI: http://dx.doi. org/10.5334/cstp.91

Submitted: 25 November 2016 Accepted: 25 November $2016 \quad$ Published: 08 December 2016

Copyright: $\odot 2016$ The Author(s). This is an open-access article distributed under the terms of the Creative Commons Attribution 4.0 International License (CC-BY 4.0), which permits unrestricted use, distribution, and reproduction in any medium, provided the original author and source are credited. See http://creativecommons.org/licenses/by/4.0/. 